\title{
Extreme hydroclimatic events in rural communities of the Brazilian Amazon: local perceptions of change, impacts, and adaptation
}

\author{
Tiago Almudi ${ }^{1,2}$ (D) A. John Sinclair ${ }^{2}$
}

Received: 15 December 2020 / Accepted: 9 November 2021 / Published online: 24 February 2022

(c) The Author(s), under exclusive licence to Springer-Verlag GmbH Germany, part of Springer Nature 2022

\begin{abstract}
The Intergovernmental Panel on Climate Change Fifth Assessment Report reveals vast evidence of increasing climate variability and a higher frequency and intensity of extreme events. Vulnerable regions to such disturbances have been widely studied in some areas, but considerably less is known about other vulnerable regions that are key to global climatic regulation, such as Amazonia. In terms of the human dimensions of climate impacts, rural and indigenous communities in developing regions are among the most vulnerable due to their limited economic capital and direct reliance on natural resources. The purpose of this research was to reveal local perceptions about the impacts of, and adaptations to, recent climatic and associated hydrological changes caused by extreme events in the Brazilian Amazon. We worked in severely impacted rural Amazonian riverine communities utilizing a qualitative case study approach that included interviews, observation while living in the community, and participatory mapping. Our results indicate that participants perceived that there has been an increased occurrence and intensity of hydroclimatic events in the last decade, especially extreme floods. Findings also show that the repeated occurrence of extreme floods resulted in severe impacts, including some that had never been experienced by the local communities, such as the complete loss of perennials. We found that a wide range of locally devised responses was implemented, despite incipient governmental support. Data also showed that responses have evolved significantly over time due to local experience with repeated extreme events. A variety of factors also affected participants' abilities to respond to hydroclimatic changes, notably information exchange among farmers and access to technological advancements.
\end{abstract}

Keywords Climate change $\cdot$ Community-based adaptations $\cdot$ Vulnerability $\cdot$ Drivers of change $\cdot$ Rural communities Brazilian Amazon

\section{Introduction}

Climate change (CC) is considered one of the main challenges to humanity in the twenty-first century (e.g., Fedele et al. 2020). Much of the associated research has focused on two general areas: the physical aspects (IPCC 2013) and

Communicated by Stacy-ann Robinson

Tiago Almudi

tiago.almudi@ibge.gov.br

A. John Sinclair

john.sinclair@umanitoba.ca

1 Instituto Brasileiro de Geografia e Estatística (IBGE), Nossa Senhora das Graças, Rua Nova Palma 200, Manaus, AM 69053-578, Brazil

2 Natural Resources Institute (NRI), University of Manitoba, 202-70 Dysart Road, Winnipeg, MB R3T 2M6, Canada the human dimensions (IPCC 2014a, b). Recent Intergovernmental Panel on Climate Change (IPCC) reports have shown clear evidence of increasing climate variability and a higher frequency and intensity of extreme events (IPCC 2018; 2019a). Vulnerable regions to such disturbances have been widely studied in some areas, such as the Canadian Arctic (e.g., Stroeve et al. 2012) and small island states (e.g., Klöck and Nunn 2019). Considerably, less is known about other vulnerable regions, such as Amazonia, that are key to global climatic regulation (Snyder 2010). For instance, little can be found in AR5 about the sequence of extreme flooding and hydrological droughts that have affected the region during the last decade (IPCC 2014b; Marengo and Espinoza 2016).

Regarding human dimensions, recent research on the effect of CC indicates that it has caused severe impacts on rural communities all over the world (IPCC 2019a; Ahmed et al. 2021). In fact, rural and indigenous communities in 
Fig. 1 Conceptual model for community-based adaptation to climate change

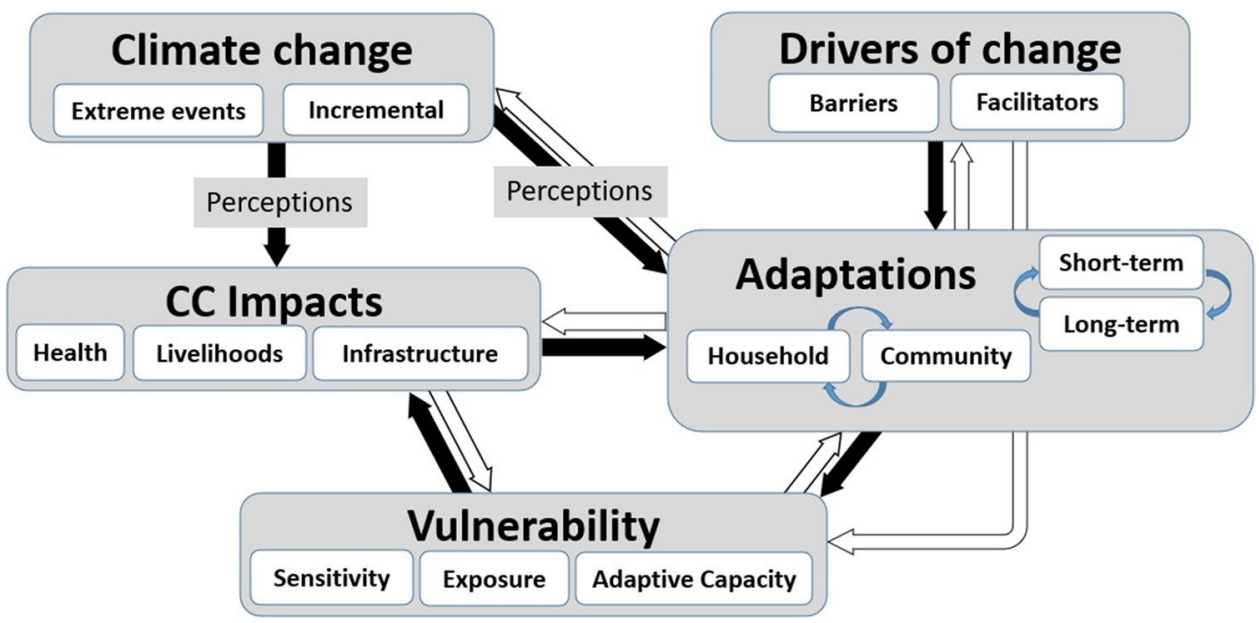

developing regions are identified as being among the most vulnerable due to their direct reliance on natural resources, limited economic capital (Moftakhari et al. 2021), marginalization in decision-making, and, in many cases, "absence of recognized rights over their territories and resources" (Nakashima et al. 2012:8). Climate change impacts on human systems are common in three dimensions: human health, infrastructure, and livelihoods (Dasgupta et al. 2014). A review of over 400 case studies on how CC affects indigenous people demonstrated that impacts on livelihood are the most common (Galloway McLean 2010). Rural communities typically have limited access to goods and services, and impacts on their livelihoods tend to be quite harmful (IPCC 2019b), often leading to poverty traps (Olsson et al. 2014).

Although vulnerable to $\mathrm{CC}$, rural communities are also usually well-equipped to respond to changes due to their history of adaptation, often grounded in local knowledge (Adger 2006). Underscoring this, AR5 partially shifts away from a focus on engineering structures for $\mathrm{CC}$ mitigation to considering the social dimension of responses, including community-based adaptations (CBA) (Noble et al. 2014). A local community-driven approach to adaptation "takes context, culture, knowledge, agency, and preferences of communities as strengths" (IPCC 2014b:1762). It focuses on the locally devised and implemented adaptations based on a bottom-up and learning-bydoing paradigm (McNamara et al. 2020). In this context, community self-organization is defined as the bottom-up process through which groups and communities in civil society organize to take collective action, thus aiming to advance their own agendas as opposed to market or government-oriented approaches (Atkinson et al. 2017). CBA allows for taking advantage of local epistemologies and experiences to explore new and expand already-tested solutions. "Given that climate change impacts, appropriate responses, and, to some extent, adaptive capacity, are location-specific, adaptation at the community level is critical to the process of adaptation" (Bryan and Behrman 2013:2).

Human adaptation occurs in response to a variety of changes that are very much context-specific (Heffernan 2012). For this reason, CBA has increasingly considered socio-economic drivers of vulnerability together with climatic risks (Jamero et al. 2018). Klein et al. (2014:902) indicate that adaptations are influenced by "the rate of climate change as well as rates of economic development, demographic change, ecosystem alteration, and technological innovation." The existence of multiple stressors is often more harmful to rural communities than the impacts of $\mathrm{CC}$ and, therefore, should not be overlooked (Räsänen et al. 2020). As CC is only one of many drivers of change, accounting for the context is essential for identifying how other forces constrain, enable, or make adaptation more flexible (Nakashima et al. 2012). The purpose of this research was to reveal local perceptions about the impacts of, and adaptations to, recent climatic and associated hydrological changes caused by extreme events in the Brazilian Amazon. Our approach considers social and ecological context within communities by accounting for how current drivers of change function as barriers and facilitators for adaptation.

\section{Conceptual model}

In order to present our data and explore outcomes related to our purpose, we have developed a conceptual model based on our consideration of the literature, as outlined in Fig. 1. Starting with a climate change event, such as extreme flooding, the model suggests the interactions among key CBA concepts with the solid black arrows indicating the relations that were the focus of this study. For instance, although adaptative actions feedback into climatic changes (white arrows), due to scope limitation, we chose not to focus on those relations but rather on how changes in climate and other drivers triggered adaptive actions (black arrows). 
Perceptions of changes in the climate and river cycle were used as an entry point for our discussions with participants. Based on the IPCC's (2018:557) definition of "risk perception," we consider "perceptions of change" as "the subjective judgment that people make about the characteristics and severity of changes." Local perceptions are a common theme in the literature on CC in Amazonia and elsewhere (e.g., Altea 2020; Platt et al. 2021), and like Hasan and Kumar (2019), we recognize that these perceptions of change and impacts are necessary precursors of adaptation.

For the purpose of this study, impacts are defined as the consequences, outcomes, or effects of climatic and associated hydrological changes and extreme events on natural and human systems, based on IPCC 2019a. We focused on the impacts on livelihoods, infrastructure, and human health, all recognized in the literature as relevant impact areas (Dasgupta et al. 2014; IPCC 2019a). A vulnerability lens was used to explain the differential impacts among communities and households based on their adaptive capacity, exposure, and sensitivity to changes (Adger 2006). A system's vulnerability to change is defined as the "propensity or predisposition to be adversely affected" (IPCC 2019b:826) which is a function of the character, magnitude, and speed of changes (Adger 1999).

Human adaptation to $\mathrm{CC}$ is central to our conceptual framework. Adaptation to $\mathrm{CC}$ is defined as "the process of adjustment to actual or expected climate and its effects. In human systems, adaptation seeks to moderate or avoid harm or exploit beneficial opportunities" (IPCC 2019a: 678). We draw on the CBA approach (Noble et al. 2014) to focus on locally devised adaptations implemented at the household and community levels. This approach gives attention to the short-term and long-term responses that offer enhanced resilience (Wilson 2012) and sustainable livelihood thinking (Scoones 1998).

Additional internal and external drivers of change either reinforce or soften community vulnerability to hydroclimatic changes by, for example, acting as barriers to and facilitators of adaptation. We define barriers as "factors that make it harder to plan and implement adaptation actions... [and] restrict the variety and effectiveness of options for actors to secure their existing objectives," and facilitators as "factors that make it easier to plan and implement adaptation actions, that expand adaptation options or that provide ancillary co-benefits" (Klein et al. 2014: 907). Accounting for the constraining and enabling factors of adaptation is key to understand climatic change contexts (Piggott-McKellar et al.2019).

\section{Choice of the study area}

Magrin et al. (2014) point out vast evidence of increases in extreme climatic events in South America. In Amazonia, studies have pointed out that river level variability has been increasing since the 1970s (e.g., Satyamurty et al. 2013), with both hydrological analyses and local observations indicating that variability has increased with higher intensity and frequency of extreme hydroclimatic events in the last two decades (e.g., Marengo et al. 2018). Extreme flooding and hydrological droughts have recently severely impacted rural Amazonian ribeirinho communities (Marengo and Espinoza 2016). For example, in 2010, the Manaus gauge station registered the lowest river level since records started to be kept in 1902 (Lewis et al. 2011) and, only two years later, recorded its highest level (Marengo et al. 2013). The second-highest level was registered in 2009 (Chen et al. 2010). In addition, the three floods from 2013 to 2015 were also among the nine highest on record at that point (Marengo and Espinoza 2016; ANA 2021), and 2005 registered the eighth-lowest nadir since 1902 (ANA 2021). Such extreme events were previously predicted to happen only once per century (Marengo and Espinoza 2016).

Eleven municipalities on the margins of the Amazonas River, Central Amazon, were selected for this study using several criteria: location in a productive rural region; suffering considerable impacts of hydroclimatic variability in the last decade; providing a mix of floodplain and upland environments, allowing comparison between those environments; providing relatively easy access to Manaus - the Amazonas State capital. The municipalities considered have a combined estimated population of 455,372 people in 2020 (IBGE 2021), with the most recent national census indicating that $45 \%$ of the population lived in rural areas, mostly in riverine communities, which was the focus of our research. When searching for communities within the study area to participate in research, we considered those that had higher levels of community self-organization, were willing to participate, had at least 30 households, and had accommodation availability with a good level of personal security. These criteria together with the availability of individual accommodation and personal security for the leading author led to the selection of the two villages described below.

\section{Research approach and methods}

Being exploratory research, we utilized a qualitative case study approach in order to gain a broad understanding of complex issues in a relatively limited amount of time without attempting to manipulate the phenomenon of interest (Creswell and Creswell 2018). Fieldwork was carried out in two phases over a 10-month period. Phase one lasted for approximately 3 months, with data collection beginning in November 2015. We conducted 56 interviews in this phase: 


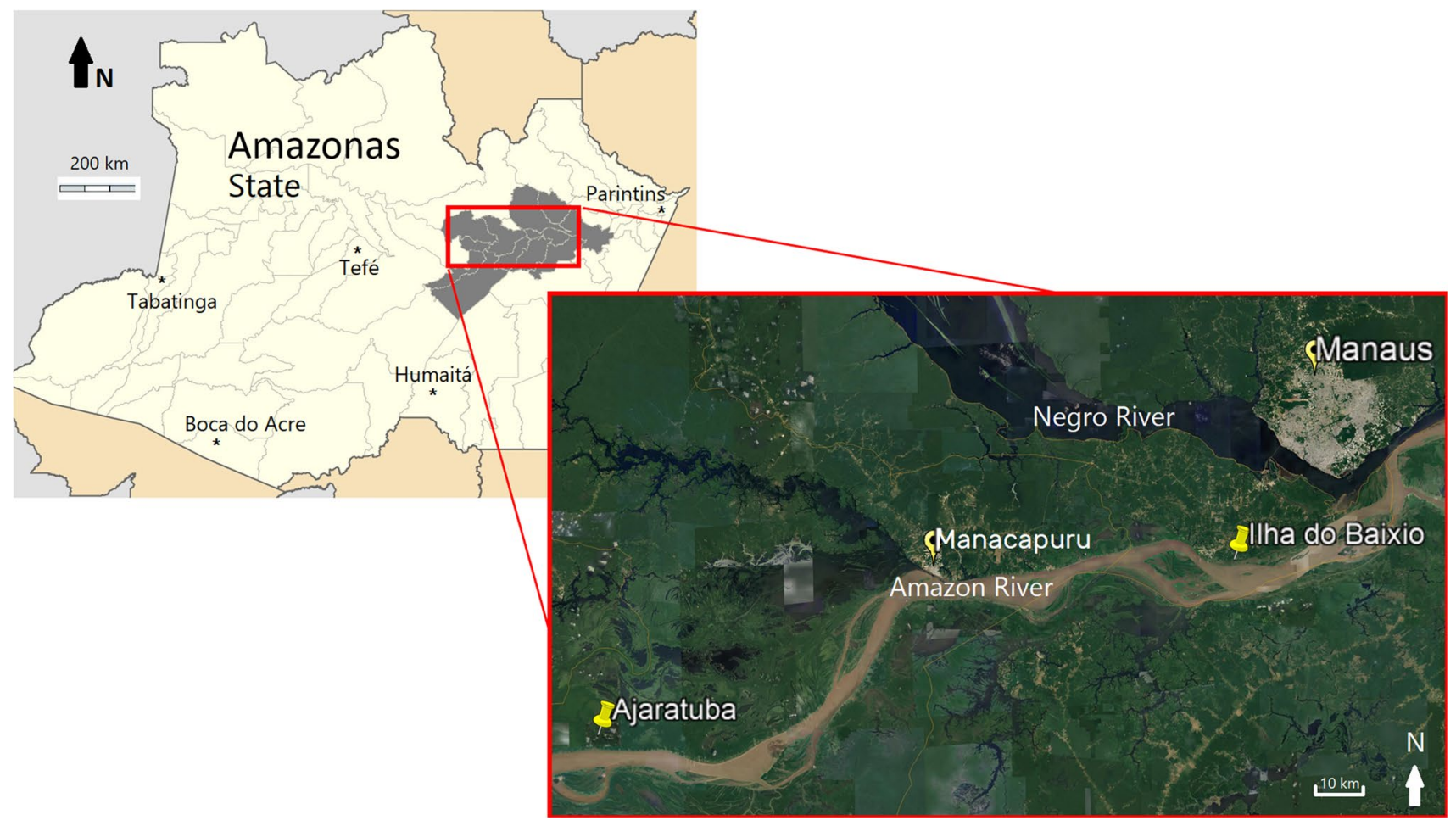

Fig. 2 Two study communities within the larger (gray) study area in Amazonas, Brazil

17 Amazonas State Rural extensionists, ${ }^{1} 22$ community members, eight other government representatives, four farmer and fisher labor unions or association representatives, four NGO employees, and one federal university professor. We sought agents and employees that worked closely with the communities for participation. Due to their close relationship and constant presence in the field, their accounts were considered as an additive to our understanding of how communities perceive change. Community elders, representatives, leaders, and knowledgeable members were also sought for participation. Interviews took between one and one and a half hours, with the data provided by participants compiled in field notebooks.

Two of the 19 communities visited in the first phase were selected as case studies for the second phase, namely Ajaratuba and Ilha do Baixio (Fig. 2). Both communities are relatively isolated, being reachable only through water access, and are around $4 \mathrm{~h}$ and $18 \mathrm{~h}$ away respectively from Manaus by regular boat transportation. Except for having a church and a primary school, the communities lack other facilities. Like other rural Amazonian communities, they also rely on diverse and non-specialized livelihoods (Adams et al. 2009). We found that their livelihoods involve various combinations

\footnotetext{
1 Amazonas State Agency of Technical Assistance and Rural Extension (IDAM, in the Portuguese acronym).
}

of small-scale family-based crop and animal husbandry, fisheries, and the extraction of timber and non-timber forest products (see also Moran 1984; Nugent 2009).

Phase two relied more heavily on participant and nonparticipant observation carried out by the lead author who lived in the communities for 7 months. A participant observation guide was used to assist in keeping track of activities observed, such as participants altering their means of transportation and increasing their reliance on fisheries during the flood period. In phase two, 17 community members of Ajaratuba and 20 from Ilha do Baixio were interviewed. Participatory mapping exercises with six participants in each community were carried out to increase understanding of the spatial distribution of impacts and adaptations.

Semi-structured interviews, participant observation guides, and participatory mapping exercises were designed to explore participants' perceptions of hydroclimatic changes and associated impacts on their livelihoods, infrastructure, and health, following our conceptual model. For instance, community participants were asked whether they noticed changes in the weather and river levels over the last few years (especially from 2009 on) and what were the impacts of those changes on their lives and livelihoods. Institutional agents were asked similar questions, aiming to understand the views of the communities they worked with. The complete interview guides are available in Appendices 1 to 3. Data-gathering procedures also investigated the locally devised short-term and long-term 
Table 1 Percentage of phase one interviewees mentioning hydroclimatic changes

\begin{tabular}{lllll}
\hline Hydroclimatic changes & Total $(n=54)$ & $\begin{array}{l}\text { Community } \\
\text { members } \\
(n=22)\end{array}$ & $\begin{array}{l}\text { Government } \\
\text { officials }(n=24)\end{array}$ & $\begin{array}{l}\text { Others (NGO, university, } \\
\text { fisher agric. org.) }(n=8)\end{array}$ \\
\hline Extreme flood & $70 \%$ & $77 \%$ & $67 \%$ & $63 \%$ \\
Stronger summer & $48 \%$ & $55 \%$ & $42 \%$ & $50 \%$ \\
Unpredictability & $19 \%$ & $27 \%$ & $8 \%$ & $25 \%$ \\
Extreme drought & $15 \%$ & $18 \%$ & $13 \%$ & $13 \%$ \\
Intense storm & $7 \%$ & $9 \%$ & $8 \%$ & $0 \%$ \\
Lack of repiquete $*$ & $6 \%$ & $5 \%$ & $4 \%$ & $13 \%$ \\
Quick river drop & $6 \%$ & $5 \%$ & $8 \%$ & $0 \%$ \\
Lack of friagem $* *$ & $4 \%$ & $0 \%$ & $8 \%$ & $0 \%$ \\
\hline
\end{tabular}

*Repiquete: hydrological phenomenon in that the river level stops rising or receding and does the opposite for a short period, typically for 1 or 2 weeks

**Friagem: climatic phenomenon in which the temperature drops suddenly for a few days (around $3^{\circ} \mathrm{C}$ or $4^{\circ} \mathrm{C}$ for about 5 days in Amazonas State) adaptations and their role in decreasing vulnerability to hydroclimatic changes. The barriers and facilitators to adaptation were taken into consideration to increase our understanding of relevant drivers of change affecting communities and their vulnerability to changes.

A validation workshop was conducted in each community at the end of the fieldwork, where preliminary findings and analyses were presented, followed by a discussion, allowing participants to ask questions and provide further feedback. The workshops lasted for approximately two and a half hours each, with 31 participants in Ajaratuba and 45 in Ilha do Baixio. Findings were also validated through memberchecking, prolonged engagement in the field, data source, and methods triangulation, and detailed thick descriptions (Creswell and Poth 2018).

All interviews were fully transcribed, and the data were analyzed for themes and patterns using NVivo 11 Starter software. The data were first analyzed according to the categories drawn from theory (e.g., short- and long-term responses) and then in themes that emerged from the data. Data analysis was accomplished following the steps proposed by Creswell and Poth (2018) for the scrutiny of qualitative data, which included (1) organizing and reading through the data; (2) detailed analysis with data coding; (3) description and representation of findings, with the use of quotes and tables, examples; and (4) interpretation of findings in relation to research objective and the relevant literature.

\section{Research findings in relation to the regional context}

\section{Perception of hydroclimatic changes}

Participants were asked in phase one about changes in the climate and river cycle (i.e., hydroclimatic changes). Table 1 presents the percentage of participants that mentioned each of the eight grounded categories noted. Although our intent was not to quantify participants' perceptions of change, the proportion of participants who mentioned each change does provide a good picture of the changes that are perceived as being most relevant locally. The perceptions of phase 1 community and non-community members did not differ significantly and were also aligned with phase 2 participants' perceptions. Based on these answers, we focused our investigation of impacts and responses on the three of the most mentioned changes, i.e., extreme floods, extreme droughts, and hotter, drier summers.

Extreme floods were by far the extreme hydroclimatic event mentioned most often by interviewees. The extreme floods occurring from 2009 on were often cited by participants, and their identification of these events agreed with the physical data reported above. Changes noted included that high ${ }^{2}$ floods are reaching even higher levels, occurring at a greater speed from the onset, taking longer to recede, becoming more recurrent, and ending in overall higher water levels (i.e., high water levels during the ebb phase). These themes crossed all the sectors that we interviewed, with a widespread agreement in the data. There was also agreement among participants that the last four floods at the time of data collection, from 2012 to 2015 , were extreme floods.

Interviewees in phase one also widely cited 2005 and 2010 as extreme hydrological droughts, also corroborating the physical data and literature. Official data demonstrates that, in fact, river levels in these years were among the lowest ever recorded in the Manaus gauge station: 2010 was the very lowest and 2005 was the 8th lowest river level, reaching respectively $13.63 \mathrm{~m}$ and $14.75 \mathrm{~m}$ (ANA 2021). Participants

\footnotetext{
${ }^{2}$ High floods are those reaching higher than average levels but not enough to be considered an extreme event.
} 
Table 2 Impacts of the main hydroclimatic changes and extreme events on rural communities

\begin{tabular}{|c|c|c|c|c|c|}
\hline Livelihoods & Freq & Infrastructure & Freq & Health & Freq \\
\hline \multicolumn{6}{|l|}{ Extreme flooding } \\
\hline Loss of crops, seeds, propagules & High & Deterioration of houses/buildings & High & Dangerous wildlife (snakes) & Low \\
\hline Shorter crop season & High & Loss of furniture and appliances & High & Lack of food and clean water & Low \\
\hline Animals loss, lower productivity & Med & Damage of materials due to high humidity & Med & Increase in skin infections & Low \\
\hline $\begin{array}{l}\text { Perennials loss, lower productiv- } \\
\text { ity }\end{array}$ & Med & Electricity grid affected & Low & Migraine, headache, back pain & Low \\
\hline Increased fish stocks & Med & Land loss due to riverbank slumps & Low & Drowning & Low \\
\hline \multicolumn{6}{|l|}{ Extreme hydrological droughts } \\
\hline Fish mortality (in lakes, channels) & High & Difficult access and transportation & Med & Lack of potable water & Low \\
\hline Produce loss (difficult transport) & High & Increased costs of merchandise & Med & Difficult transport of patients & Low \\
\hline Cattle death (due to lack of water) & Med & Stranded boats, speed boat crashes & Med & Dangerous wildlife (alligator) & Low \\
\hline Difficult access to timber/NTFP & Med & Damage to fishing gear & Low & Accidents with speed boats & Low \\
\hline Difficult access to fishing areas & Med & Damage to floating houses on dry land & Low & Diarrhea (polluted water) & Low \\
\hline \multicolumn{6}{|l|}{ Drier and hotter summers } \\
\hline Reduced crop productivity & High & Burned house and crop in uplands & Med & Headache, uneasiness, fatigue & Low \\
\hline Unable to grow green vegetables & High & Material losses to fire & Med & Respiratory diseases & Low \\
\hline Lower pasture productivity & Med & Loss of productive material to fire & Med & Eye infection due to smoke & Low \\
\hline Fish mortality (in aquaculture) & Med & Loss of houses to fire & Low & Emotionally shaken due to fire & Low \\
\hline Loss of trees (also due to floods) & Low & Contributes to impacts of droughts & Low & Insolation & Low \\
\hline
\end{tabular}

of phase two corroborated the results of phase one and added that 2015 was also a severe drought. Participants in both research phases also mentioned that storms (i.e., heavy rain with strong winds) are becoming more common and more intense. Such perceptions of extreme events fell in line with what others have reported in the regional literature (e.g., Camacho Guerreiro et al. 2016; Oviedo et al. 2016) and corroborated physical science data (e.g., Marengo and Espinoza 2016).

The second most mentioned change in phase one was that summers are gradually becoming "stronger." In other words, the seasons have been presenting a combination of lack of rain and high temperatures beyond what participants perceived as average. Several participants mentioned 2015 as one of the strongest summers they experienced in the last decades. This corroborates the literature in that 2015 was the hottest year, with the lowest precipitation levels, since 1986 (D’Avila Junior and Vieira 2019). Participants also mentioned the unusual number of accidental fires happening in 2015, corroborating the Civil Defense reporting. Participants in phase two supported these views, and most mentioned that the climate has been changing toward stronger summers more noticeably in the last 10 to 20 years. "I remember that ten years ago the sun was not this hot, we would work until 11:00 a.m. and then go back to work at 1:00 p.m. We were used to that. Now, when it is 3:00 p.m. we still cannot get out of the house" (Josivan). Participants also noted that summers used to be windier which, together with the decrease in shade area due to deforestation, there is an increase in the "feels-like" temperature.

Participants in both phases commonly mentioned that climatic events are becoming more variable, with a higher range of intensity within shorter timeframes: "the river is unpredictable. We observe, we live here the whole life by the river, but you don't have an experience that works..." (José Rubens). The timing of rainy and dry seasons, rising and receding river levels, were presented as being harder to predict in the last years: "No one can predict how the next flood will be anymore" (Edmilson). There was no exact point in time which participants identified as being a turning point, but in general, they agreed that they already started to notice changes in the second half of the 1990s, intensified during the 2000s and reached their peak more recently. Ribeirinhos elsewhere have also widely reported their perception of lower hydroclimatic predictability (Pinho et al. 2015; Oviedo et al. 2016).

\section{The impacts of hydroclimatic variability}

Participants of both study phases reported a wide range of impacts in relation to the parent themes of livelihoods, infrastructure, and health (Table 2). We have considered low (1-25\%), medium (26-50\%), and high (51\% and above) frequency of answers in relation to our themes, as reflected in Tables 2, 3 and 4, keeping in mind that this was a qualitative research undertaking. Questions focused on the three most cited hydroclimatic changes: extreme floods, extreme 
Table 3 Short-term and longterm responses to hydroclimatic variability

\begin{tabular}{|c|c|c|c|}
\hline Short-term responses & Freq & Long-term responses & Freq \\
\hline \multicolumn{4}{|l|}{ Extreme flooding } \\
\hline Improvised second floor on house & High & Focus on fast-growing crops & High \\
\hline Increase fishing for subsistence & High & Focus on flood-resistant crops & Med \\
\hline Harvest unripe crops & High & Uplift houses and community buildings & Med \\
\hline Platforms on stilts for storage & High & Reduce or extinguish herds & Med \\
\hline Transport cattle to rented upland fields & High & Increase number of floating houses & Low \\
\hline Exchange of labor to harvest quickly & Med & Migrate to uplands or urban areas & Low \\
\hline Small softwood planting beds on stilts & Med & Large hardwood planting beds on stilts & Low \\
\hline Board dikes to delay inundation & Low & Acquire upland fields to transport cattle & Low \\
\hline \multicolumn{4}{|l|}{ Extreme hydrological droughts } \\
\hline Produce lighter crops (easier to transport) & Med & Pump potable water from uplands & Med \\
\hline Switch fishing techniques & Med & Collect rain water (government program) & Low \\
\hline Alternative routes (motorcycle + boats) & Med & Build embankment bridges & Low \\
\hline Switch from lake fishing to river fishing & Low & Dig proper wells or holes by the riverbank & Low \\
\hline Fishers switching to crop agriculture & Low & Collectively building dikes in creeks & Low \\
\hline $\begin{array}{l}\text { Treat the river water (hypochlorite, sieve, } \\
\text { boil) or buy potable water }\end{array}$ & Low & Bolinete (device to pull boats to the land) & Low \\
\hline $\begin{array}{l}\text { Collectively dig ditches on silted lakes } \\
\text { for school boats to transport students }\end{array}$ & Low & & \\
\hline \multicolumn{4}{|l|}{ Drier and hotter summers } \\
\hline Reduce working hours & High & Irrigation system for fast-growing crops & High \\
\hline $\begin{array}{l}\text { Quit planting in summer without irriga- } \\
\text { tion }\end{array}$ & High & Fast-growing crops under shadow screen & High \\
\hline Wait to plant (soil correction after rain) & High & Fan and air conditioner & Med \\
\hline Use more pesticides for caterpillar plague & High & More resistant varieties (e.g. plantain) & Low \\
\hline $\begin{array}{l}\text { Leave the uncovered area for breaking } \\
\text { fire }\end{array}$ & High & Switch from cattle to buffalo & Low \\
\hline Quit sensitive crops (e.g., cucumber) & Med & Introduce aerators to fish ponds & Low \\
\hline Provide corn ration to cattle & Med & & \\
\hline
\end{tabular}

Table 4 Drivers of change influence on adaptation to hydroclimatic variability

\begin{tabular}{|c|c|c|}
\hline Driver & Strength & Influence on adaptation \\
\hline \multicolumn{3}{|l|}{ Internal drivers of change } \\
\hline $\begin{array}{l}\text { Self-organizing and social cohe- } \\
\text { sion }\end{array}$ & High & $\begin{array}{l}\text { Enable collective responses and facilitate access to governmental programs }(+) \\
\text { Enable mutual household support and social learning }(+)\end{array}$ \\
\hline Capitalization & High & $\begin{array}{l}\text { Financial resources allow for a wider range of responses }(+) \\
\text { Lack of resources limits some responses }(-)\end{array}$ \\
\hline Religion and spirituality & Medium & $\begin{array}{l}\text { Faith counteracts action when denied real changes evidence }(-) \\
\text { Faith and hope are associated with serenity to overcome losses and braveness to innovate }(+)\end{array}$ \\
\hline Culture, habits, and mindsets & Medium & $\begin{array}{l}\text { Relying on paternalistic policies limits some responses }(-) \\
\text { Culture is closely related to the local environment, making them prone to find solutions to } \\
\text { stay rather than migrating }(+)\end{array}$ \\
\hline \multicolumn{3}{|l|}{ External drivers of change } \\
\hline Access to market & High & $\begin{array}{l}\text { Proximity to large markets enables a wider responses range }(+) \\
\text { Difficult produce trade is a relevant bottleneck for action }(-)\end{array}$ \\
\hline Technology & Medium & $\begin{array}{l}\text { Access to technology enables learning and innovation }(+) \\
\text { Reliance on technology erodes some traditional knowledge }(-)\end{array}$ \\
\hline Government programs & Medium & $\begin{array}{l}\text { Lack of programs to decrease vulnerability to extreme events }(-) \\
\text { Emergency aid enables households to cope with flood impacts }(+)\end{array}$ \\
\hline Social networks & Medium & $\begin{array}{l}\text { Exchange of materials and knowledge among farmers and with governmental agents fosters } \\
\text { learning and enable responses }(+)\end{array}$ \\
\hline
\end{tabular}

(+) facilitator; (-) barrier. 
hydrological droughts, and stronger summers. Impacts of extreme floods were mentioned the most by participants, reflecting the repeated occurrence of such events in the last 10 years. In general, participants spontaneously mentioned livelihood impacts the most and health impacts the least, likely indicating their perception of the relative importance of such impacts. Plus, health impacts are usually idiosyncratic, while livelihood and infrastructure impacts, for the most part, often affect several households at once.

The data demonstrate that the perception of impacts reflected the vulnerability of communities to hydroclimatic changes, but this depended mostly on their geographic location and sources of livelihood. Geographic location determined the exposure to changes, with communities located in uplands suffering the most with the occurrence of strong summers and the least with hydrological droughts. Communities located by the main river stem did not suffer impacts of hydrological droughts as much as those located on the margins of lakes and river arms. Communities and households located on lower floodplain areas were the most exposed to extreme floods but also were more prepared to handle these events. Differential impacts were also determined by livelihood sources. As most participants relied on crop agriculture, extreme flooding and stronger summers were seen as important hazards. Those that relied mostly on fisheries were more concerned about the impacts of extreme hydrological droughts, while they felt that extreme floods actually brought positive impacts.

The setting of new records for river nadir and zenith in the last decade together with the increase in the occurrence of extreme events established a considerably higher severity of impacts on the local population. Impacts that were commonly observed in years of regular flooding became considerably more severe, such as the damage and even loss of houses, due to more intense currents and river waves. Moreover, new types of impacts were observed in some regions. "After the big floods new types of weeds that we didn't know showed up" (Nerinho). The higher severity of impacts was also determined by the combination of hostile conditions. For example, extreme floods caused the siltation of bodies of water, which made fish stocks more vulnerable to the occurrence of more intense hydraulic droughts. Extreme floods also pushed the starting of the planting season to the peak of summer, which caused crops not to sprout well due to hotter and drier conditions.

The regional literature reported similar impacts of extreme floods on small-scale agriculture and fisheries, including loss of crops (Sherman et al. 2015) and lower crop, livestock and short-term fisheries productivity (Brondízio and Moran 2008; Pinho et al. 2015). Our findings of positive correlations between extreme floods and an increase in fishery yields in the following years also corroborate Castello et al. (2015). Findings related to property loss and damage are also underscored by Marengo et al. (2012) and Maru et al. (2014). We found a scarce reference in the regional literature about the health impacts of extreme flooding. Examples of indirect health impacts were increased food insecurity (Pinho et al. 2015) and lower quality of potable water (Brondízio et al. 2009), which were also reported by our participants.

Regionally, we heard reports of increased fish mortality, underscoring Castello et al. (2015) and Röpke et al. (2017), and decreased captures due to difficulty accessing fishing grounds, as also found by Anderson et al. (2011) and Tomasella et al. (2013). The literature presents plenty of infrastructure impacts of extreme droughts including navigation interruption, stranded boats, and isolated communities (Pinho 2016), as we also found.

\section{Adaptation to hydroclimatic variability}

A wide range of responses to recent hydroclimatic changes was reported by participants in both study phases (Table 3 ). Although ribeirinho's lives are already adapted to the river cycles (Arce-Nazario 2011), our findings indicate that there are continual fine adjustments to the interannual flood-pulse variability (see also, Pinedo-Vasquez et al. 2002; Smith 2011). The frequency of the responses we found regarding adaptation is likely related to the recent repetition of extreme floods since the last extreme droughts occurred long ago (see "Perception of hydroclimatic changes"). Findings also demonstrate the higher number and frequency of short-term responses in comparison to long-term responses. Most responses were related to avoiding and overcoming livelihood impacts, although responses to infrastructure and health impacts were also reported, such as building higher houses to avoid inundation and reducing working hours to avoid higher temperatures. The overwhelming majority of responses were devised at the household level and did not rely on governmental or other kinds of external support. An exception was gutters installed through a program of the Ministry of Social Development to gather rainwater in water tanks. Examples of community-based responses included gatherings to fight accidental fire in upland communities and protests against speed boats passing by flooded residential areas that were causing severe impacts to houses and community infrastructure due to the boat waves created.

Adaptations to extreme flooding found both in our case studies and by others included transporting cattle to uplands (Oviedo et al. 2016), building planting beds on stilts (Nascimento 2017), focusing on fast-growing crops and cultivars (Osuna et al. 2014; Sherman et al. 2015) and flood-resistant crops (Vogt et al. 2015), reducing herds (Nascimento 2017), increasing the rate of migration (Adams et al. 2009; Sherman et al. 2015), building improvised second floors (Padoch and Pinedo-Vasquez 1991; Sherman et al. 2016), increasing 
the number of floating houses (Alencar et al. 2014), and increasing fishing for subsistence (Takasaki et al. 2010; Drapeau et al. 2011). Nevertheless, some of the participant adaptations, such as building dikes to protect crops from rising waters and uplifting houses using hydraulic jacks, have not been reported elsewhere, representing innovations that have only recently been implemented in the study area.

Participants' reports revealed that responses to extreme flooding have evolved significantly during the last decade as a result of the repetition of impacts. In the 2009 extreme flooding, for example, many households did not store plantain pseudostems, as they were expected to sprout spontaneously after regular floods. However, keeping these propagules on top of rafts and platforms on stilts turned into common practice as extreme floods became more frequent so that they would sprout. Households also started to become better prepared by keeping boards to be used in a variety of responses (e.g., putting planting beds on stilts and temporary improvised floors), renting upland fields in advance to keep their herds, and acquiring food for the cattle. The building of board dikes is an emblematic example of response improvement. "There were many changes along the time. Dikes started being made with logs coming down the river and water grass" (Nerinho). With increased experience, they tested and improved dikes with the use of sewed boards, sturdier stakes, and plastic tarpaulin to build higher and more resistant dikes.

Adaptations to extreme droughts and to hotter and drier summers are not well documented in the regional literature. In fact, the vast majority of examples informed by our participants have not been reported elsewhere. A possible reason for that is the higher severity of impacts of the last sequence of extreme flooding in comparison to the impacts of extreme droughts and stronger summers in the study communities. Adaptations that our participants reported and we in some cases observed included leaving clean areas around burn sites to avoid the spread of accidental fire (Emilio et al. 2006; Brondízio and Moran 2008; Carmenta Saskia et al. 2013), building water reservoirs, and switching crops (Emilio et al. 2006).

\section{Drivers of change: barriers to and facilitators of adaptation}

Participants were asked about the main drivers of change influencing adaptation to hydroclimatic variability. Table 4 presents the positive and negative drivers that are internal and external to the communities. The strength of drivers was determined not only by the frequency of answers but also by a qualitative analysis of participants' accounts of each. Communities with a higher degree of self-organization and social cohesion were found to implement collective responses that were not seen in other communities, such as the protest against the impacts of river waves created by speed boats. They were also able to both request governmental support more efficiently and to access environmental programs and aid resources. Community self-organization and social cohesion were usually strengthened by the presence of strong local institutions. "Our community has always been a reference because when we plan something important in the community, all the community organizations work together" (Nei).

During the last hydroclimatic extreme events reported in this study, there were no governmental programs in place to increase the adaptive capacity of rural communities. There was also no warning system to inform locals about the probability of extreme events and their characteristics, such as the expected duration. As a response to extreme events in Amazonia, the federal and state governments repeatedly provided millions of dollars in short-term aid, instead of addressing the factors that cause the system's vulnerability (Borma et al. 2013). One of the reasons for governments to focus on readily observable measures is that those often benefit political and election structures (Adger et al. 2011). Participants felt that, despite the palliative nature of government measures, families did benefit from the provision of groceries, wood, and cash during the flood period. A common participants' complaint was the poor rural technical assistance provided by governmental agencies: "When farmers try a new technique in here, we always get a punch first because there is none to instruct us on the right way of doing it" (Jesiel). One of the main ways participants filled this gap was by exchanging information with farmers from other communities. This has allowed participants to learn, for example, about technological improvements to agriculture such as machinery, irrigation systems, and more productive crop varieties.

\section{Interactions within our conceptual model}

We highlight here five interactions within our conceptual model that were revealed by the data. The first interaction of note is between "perception of change and impacts," as there was a strong association between the severity of social impacts and the perception of the intensity of changes. Pinho et al. (2015:651) also found that remote communities of the Brazilian Amazon, in fact, perceived flooding events as extreme "on the basis of powerful social impacts." Similar results were also found for Bangladeshi and Peruvian Amazon flood-prone communities (Sherman et al. 2015; Alam et al. 2017). Our data suggest that the households located in high floodplain areas perceived the last extreme floods as more severe than low floodplain households did. A plausible explanation is that these households had never had their houses inundated in earlier floods, while low floodplain 
households were used to inundation even in regular flooding events. Crop farmers and ranchers tended to consider the flooding events more extreme while fishers considered drought events more threatening, also due to the severity of impacts suffered (see also Castello et al. 2013).

The second interaction is between "adaptation and perception of change." Considering this interaction in the model allowed us to identify that perception of change and of associated impacts significantly influence whether and how adaptation occurs, which has also been identified in the literature (Hasan and Kumar 2019). Participants' accounts indicated that during the extreme flooding events of 2009 and 2012, most riverine families actioned almost exclusively only short-term responses to overcome flooding impacts, believing that such extreme events would take longer to happen again. This was supported by the fact that elders knew and taught that the last extreme flood of such proportions and similar impacts had taken place back in 1953. In fact, the perception that future risks are too far away was shown to, in general, prevent long-term responses (Michetti and Ghinoi 2020). Nevertheless, as extreme floods continued happening in the following years, long-term responses became more common. The benefits of long-term adaptation were then considered worth their higher costs by participants because a future extreme event seemed more probable to them, a rationale that can also be found in the literature (Bustos and Vicuña 2016).

The third interaction we highlight is between "impacts and adaptation." New types of impacts and significantly higher-intensity impacts require novel and, in some cases, transformative adaptation (Wilson et al. 2020). The innovative responses presented in "Adaptation to hydroclimatic variability," for example, would probably not have been carried out had extreme hydroclimatic events not happened. This is in line with the regional literature that presents novel responses stemming from impacts to "degrees outside living experience" (Pinho et al. 2015: 651). Some of these new responses we found included switching to fast-growing crops on riverbeds, cultivating flood-tolerant plantain varieties (see also Sherman et al. 2015, 2016), and planting grasses to protect houses from river waves (see also Oviedo et al. 2016).

The fourth interaction we considered was between "adaptation and vulnerability." Most long-term adaptative measures presented in "Adaptation to hydroclimatic variability" led to lowering community vulnerability to extreme hydroclimatic events. These included switching to flood-resistant crops to decrease sensitivity and lifting houses to reduce exposure to extreme floods. Although adaptive measures usually result in vulnerability reduction, our conceptual model led us to realize that adaptation may rather increase vulnerability. In fact, maladaptive measures usually decrease specific vulnerability while increasing a system's overall sensitivity or exposure to hazards (Juhola et al. 2016). For example, we found that farmers who cut ties with the floodplain - by selling their house and lands - are free from flooding impacts but often are not able to gain a livelihood in upland or town areas due to lack of specific knowledge, lack of employment opportunities, and scarce financial resources. The literature corroborates that migration as an emergency response to environmental hazards usually increases overall household vulnerability (e.g., McNamara et al. 2018).

Interaction between "drivers of change and adaptation" is the fifth analytical link we highlight. Community selforganization and social cohesion were found to be strong internal drivers of change, determining a wider range of community-based adaptation. For example, crops were saved due to actioning community task forces to harvest fields about to be flooded, and community groups united to provide assistance through labor - to rebuild houses that fell apartand for food donation to families that experienced major material losses. The literature notes that communities with such cooperative capacity were better equipped to adapt and therefore less vulnerable to hydroclimatic impacts than their lesser self-organized counterparts (e.g., Barnes et al. 2020), which could be at play here as well. Access to economic capital was also stressed by participants as an important driver of change supporting adaptive capacity, corroborating social sciences CC literature (e.g., Moftakhari et al. 2021). For example, the households that we were able to acquire upland property without having to sell their floodplain lands were better off when coping with extreme floods both in terms of housing safety and secure livelihood sources, as our data shows.

\section{Conclusions}

This exploratory study contributes to the $\mathrm{CC}$ adaptation literature by providing a local perspective grounded in the perceptions of participants that supports and adds to the directions noted in the literature. One contribution relates to demonstrating that the frequency and intensity of extreme climatic events have created new and significantly more severe impacts for local communities. In the worst case, such impacts could even undermine local capacities to react, as Pinho et al. (2015) also noted. Our findings are also relevant in indicating that extreme stresses require innovative and transformative forms of responses, as revealed locally, in addition to the incremental short- and long-term adaptations emphasized by the literature (Novalia and Malekpour 2020). The locally devised responses demonstrated through our cases to have the potential to impact policy-making in the region and elsewhere. Policies that learn from and support local responses have the advantages of being usually low-cost and culturally appropriate in comparison to 
external fixes. In addition, governmental policies should, at least partially, focus on strengthening self-sustaining measures for building on any developing community capacity (Robinson and Berkes 2011). Our findings certainly support the IPCC (2019b) indication that the involvement of local stakeholders and the reinforcement of their own attempts at climate adaptation improves the effectiveness of CC governance by maximizing co-benefits and minimizing trade-offs, especially for more vulnerable communities.

Our purpose was to explore local perceptions about changes and impacts due to extreme hydroclimatic events to demonstrate the local responses of riverine communities in the Brazilian Amazon. In this regard, participants established that they did clearly and correctly recognize the increased occurrence and intensity of hydroclimatic events in the last decade, especially extreme floods, as their perceptions were supported by findings of IPCC AR5 and the regional literature (e.g., Brondízio and Moran 2008; Ruiz-Mallén et al. 2017). Findings demonstrate that the repeated occurrence of extreme floods resulted in severe impacts, including some that had never been experienced by the local communities, such as the complete loss of perennial crops. We found that a wide range of locally devised responses was implemented despite the lack of governmental support. Our data also show that many of these responses evolved significantly over the last decade due to local experience with repeated extreme events, a finding that we expect will become more common in other studies, but that has not been noted yet. In fact, locals made investments in longer-term adaptation due to their repeated experiences.

Not surprisingly, we found a variety of factors affected participants' ability to respond to hydroclimatic changes, notably information exchange among farmers of the same or other communities and access to technological advancements such as irrigation systems and more flood-resistant crops. Such findings are valuable and must be tested against new evidence as extreme floods have continued to occur since the conclusion of this research. In 2019, the 6th highest river level at that time was recorded at the Manaus gauge (29.42 m), and in 2021, a new highest level was set $(30.02 \mathrm{~m})$, surpassing the $29.97 \mathrm{~m}$ registered in 2012 (ANA 2021). Given the ongoing occurrence of such events in the context of the COVID-19 pandemic, future research should consider the extent to which emergency aid provided by the Brazilian government since April 2020 has enabled ribeirinhos to improve local responses. Recent research indicates the success of such measures in safeguarding the essential needs of local Amazonian populations (Lopes et al. 2021).

As the field of CBA is still emerging and lacks a wellestablished analytical framework, our conceptual model is intended to contribute to future research, especially regarding local communities facing $\mathrm{CC}$ impacts. Our model proved valuable for revealing important linkages among key CBA concepts. While we placed emphasis on adaptation as being at the core of the model, the interactions among impacts and adaptations and barriers to adaptation provide a fuller picture of the effects of extreme weather on rural communities and their ability to change. We found, for example, that the capacity to self-organize and community cohesion worked together to help to drive change and adaptation. The model also facilitated our understanding that people's perceptions of change and the kinds of impacts they suffer will determine if, how, and when they may adapt. The model also demonstrated the strength of taking internal and external drivers of change into consideration, something that is now receiving increased recognition within the CC literature (Olsson et al. 2014). As pointed out by Fraser et al. (2011:2): "Taken together...[the] social and ecological context in which climatic problems occur is likely to be as important, if not more so than the climatic shock itself." Our findings in relation to the interaction between adaptation and drivers of change certainly support this view.

Looking into the future development of the CBA field, we envision a need for researchers to further engage with learning approaches and theories. The challenges imposed by $\mathrm{CC}$ creates room for "temporal, geographical, political, institutional learning spaces" (Robin et al. 2019:246) including experimentation and innovation (Novalia and Malekpour 2020), which some of our respondents did, at least from their point of view. As new impacts and novel responses are, to a certain extent, beyond the living experience of local populations, there is also room for research to explore the risks and costs of locally devised innovations and transformations. Transformative responses could, in fact, turn out to be maladaptive (i.e., increase vulnerability) by strengthening path-dependencies, for example, Barnett and O'Neil 2010). Finally, future research on CBA should look at the conditions for successfully scaling up local CBA initiatives into higher-level programs and policies where the fit seems right. In line with Kirkby et al. (2017), we believe that the CBA approach needs to gain efficiency by aligning theoretical development with practical lessons to improve the well-being of local communities and others among the most vulnerable to CC.

Supplementary Information The online version contains supplementary material available at https://doi.org/10.1007/s10113-021-01857-0.

Acknowledgements The authors thank the research participants in Amazonas State, Brazil. Significative insight was provided by Dr. Fikret Berkes and Dr. Mark Hudson (University of Manitoba).

Funding Funding was provided by Conselho Nacional de Desenvolvimento Científico e Tecnológico (CNPq), Brazil-248999/2013, Social Sciences and Humanities Research Council (SSHRC), Canada - 36820, and Organization of American States - 0088615. 


\section{References}

Adams C, Murrieta R, Siqueira A, Neves W, Sanches R (2009) Bread of the land: the invisibility of manioc in the Amazon. In: Adams C, Murrieta R, Neves W, Harris M (eds) Amazon Peasant Societies in a Changing Environment. Political Ecology, Invisibility and Modernity in the Rainforest. Springer, London and New York, pp 281-305. https://doi.org/10.1007/978-1-4020-9283-1

Adger WN (1999) Social vulnerability to climate change and extremes in coastal Vietnam. World Dev 27(2):249-269. https://doi.org/10. 1016/S0305-750X(98)00136-3

Adger WN (2006) Vulnerability. Glob Environ Chang 16:268-281. https://doi.org/10.1016/j.gloenvcha.2006.02.006

Adger WN, Barnett J, Chapin FS, Ellemor H (2011) This must be the place: underrepresentation of identity and meaning in climate change decision-making. Global Environmental Politics 11(2):125. https://doi.org/10.1162/GLEP_a_00051

Ahmed Z, Guha GS, Shew AM, Alam GMM (2021) Climate change risk perceptions and agricultural adaptation strategies in vulnerable riverine char islands of Bangladesh. Land Use Policy 103:105295. https://doi.org/10.1016/j.landusepol.2021.105295

Alam GM, Alam K, Mushtaq S (2017) Climate change perceptions and local adaptation strategies of hazard-prone rural households in Bangladesh. Clim Risk Manag 17:52-63. https://doi.org/10. 1016/j.crm.2017.06.006

Alencar ED, de Sousa IS, Gonçalves ACT (2014) Modes de interação com o ambiente e estratégias de subsistência dos moradores da várzea do Rio Japurá (AM). Fragmentos De Cultura 24(2):303-317

Altea L (2020) Perceptions of climate change and its impacts: a comparison between farmers and institutions in the Amazonas Region of Peru. Climate Dev 12(2):134-146. https://doi.org/10.1080/ 17565529.2019.1605285

ANA (Agência Nacional de Águas e Saneamento Básico) (2021). Dados Hidrológicos em Tempo Real. Série Histórica. Estação 14990000 Manaus. https://www.gov.br/ana/pt-br. Accessed 31 Aug 2021.

Anderson LO, Trivedi M, Queiroz J, Aragão L, Marengo JA, et al (2011) Counting the costs of the 2005 Amazon drought: a preliminary assessment. In: Meir P, Mitchell A, Marengo J, Young C, Poveda G, et al (eds) Eco- system Services for Poverty Alleviation in Amazonia. Global Canopy Programme and University of Edinburgh, pp. 97-104. https://doi.org/10.13140/RG.2.2.15265.25442

Arce-Nazario JA (2011) Managing ecosystem heterogeneity: a case study of an Amazonian floodplain landholding. Journal Sustain Forestry 30(1-2):1-19. https://doi.org/10.1080/105498110037391 22

Atkinson R, Dorfler T, Hasanov M, Rothfuss E, Smith I (2017) Making the case for self-organisation: understanding how communities make sense of sustainability and climate change through collective action. Int J Sustain Soc 9(3):193. https://doi.org/10.1504/ IJSSOC.2017.088300

Barnes ML, Wang P, Cinner JE, Graham NAJ, Guerrero AM et al (2020) Social determinants of adaptive and transformative responses to climate change. Nat Clim Chang 10:823-828. https:// doi.org/10.1038/s41558-020-0871-4

Barnett J, O’Neil S (2010) Maladaptation. Glob Environ Chang 20:211-213. https://doi.org/10.1016/j.gloenvcha.2009.11.004

Borma LS, Tomasella J, Roballo ST, Cuartas LA., Rodriguez DA, et al (2013). Impactos Dos Eventos Extremos de Seca e Cheia Sobre os Recursos Hídricos Amazônicos, Desastres Naturais e Ações da Defesa Civil. In: Borma LS, Nobre AC (eds) Secas na Amazônia. Oficina de Textos, São Paulo, Brazil.

Brondízio ES, Moran EF (2008) Human dimensions of climate change: the vulnerability of small farmers in the amazon. Philos Trans of the Royal Society 363:1803-1809. https://doi.org/10.1098/rstb. 2007.0025

Brondízio ES, Ostrom E, Young OR (2009) Connectivity and the governance of multilevel social-ecological systems: the role of social capital. Annu Rev Environ Resour 34:253-278. https://doi.org/10. 1146/annurev.environ.020708.100707

Bryan E, Behrman J (2013) Community-based adaptation to climate change: a theoretical framework, overview of key issues and discussion of gender differentiated priorities and participation CAPRi Working Paper No. 109. International Food Policy Research Institute, Washington. https://doi.org/10.2499/CAPRiWP109

Bustos ES, Vicuña SD (2016) Decision making and adaptation processes to climate change. Ambiente \& Sociedade 4:215-234. https://doi.org/10.1590/1809-4422asocex0004v1942016

Camacho Guerreiro A, Ladle R, da Silva BV (2016) Riverine fishers' knowledge of extreme climatic events in the Brazilian Amazonia. J Ethnobiol Ethnomed 12:50. https://doi.org/10.1186/ s13002-016-0123-x

Carmenta Saskia R, Luke V, Barlow PJ (2013) Shifting Cultivation and Fire Policy: Insights from the Brazilian Amazon. Hum Ecol 41(4):603-614. https://doi.org/10.1007/s10745-013-9600-1

Castello L, McGrath DG, Arantes CC, Almeida OT (2013) Accounting for heterogeneity in small-scale fisheries management: The Amazon case. Mar Policy 38:557-565. https://doi.org/10.1016/j. marpol.2012.09.001

Castello L, Isaac VJ, Thapa R (2015) Flood pulse effects on multispecies fishery yields in the Lower Amazon. Royal Society Open Science 2:150299. https://doi.org/10.1098/rsos.150299

Chen JL, Wilson CR, Tapley BD (2010) The 2009 exceptional Amazon flood and interannual terrestrial water storage change observed by GRACE. Water Resour Res 46:W12526. https://doi.org/10.1029/ 2010WR009383

Creswell JW, Creswell JD (2018) Research design: qualitative, quantitative, and mixed methods approaches, 5th edn. Sage, London

Creswell JW, Poth CN (2018) Qualitative inquiry and research design. Choosing among five approaches. $4^{\text {th }}$ edition. Thousand Oaks, Sage.

Dasgupta P, Morton JF, Dodman D, Karapinar B, Meza F, et al (2014) Rural areas. In: IPCC (2014) Impacts, adaptation, and vulnerability. Part A: global and sectoral aspects: Working Group II Contribution to the IPCC Fifth Assessment Report. Cambridge University Press, Cambridge, pp 613-657. https://doi.org/10. 1017/CBO9781107415379

D’Avila Junior JCM, Vieira AFSG (2019) Padrões pluviométricos da Cidade de Manaus-AM: 1986 a 2015. Boletim Paulista de Geografia 102:1-31. ISSN: 2447-0945.

Drapeau G, Mering C, Ronchail J, Filizola N (2011) Variabilité hydrologique et vulnérabilité des populations du Lago Janauaca (Amazonas, Brésil) Confins. Revue franco brésilienne de géographie 11https://doi.org/10.4000/confins.6904

Emilio F, Moran R, Adams B, Bakoyéma Stefano F, Boucek BT (2006) Human strategies for coping with El Niño Related drought in Amazônia. Climatic Change 77(3-4):343-361. https://doi.org/ 10.1007/s10584-005-9035-9

Fedele G, Donatti CI, Harvey CA, Lee H, Hole DG (2020) Limited use of transformative adaptation in response to social-ecological shifts driven by climate change. Ecol Soc 25(1):25. https://doi.org/10. 1016/j.envsci.2019.07.001

Fraser E, Dougill A, Hubacek K, Quinn C, Sendzimir J et al (2011) Assessing vulnerability to climate change in dryland livelihood systems: conceptual challenges and interdisciplinary solutions. Ecol Soc 16(3):3. https://doi.org/10.5751/ES-03402-160303

Galloway McLean K (2010) Advance guard: climate change impacts, adaptation, mitigation and indigenous peoples: a compendium of case studies (traditional knowledge initiative). United Nations University, Darwin. ISBN: 978-0-9807084-0-0. 
Hasan MK, Kumar L (2019) Comparison between meteorological data and farmer perceptions of climate change and vulnerability in relation to adaptation. J Environ Manage 237:54-62. https://doi. org/10.1016/j.jenvman.2019.02.028

Heffernan O (2012) Adapting to a warmer world: no going back. Nature 491:659-661. https://doi.org/10.1038/491659a

IBGE (2021). Instituto Brasileiro de Geografia e Estatística. Cidades, População Estimada 2020. https://cidades.ibge.gov.br. Accessed 26 Apr 262021.

IPCC (2013) Climate Change 2013: The Physical Science Basis. Contribution of Working Group I to the Fifth Assessment Report of the Intergovernmental Panel on Climate Change [Stocker, T.F., D. Qin, G.-K. Plattner, M. Tignor, S.K. Allen, J. Boschung, A. Nauels, Y. Xia, V. Bex and P.M. Midgley (eds.)]. Cambridge University Press, Cambridge, United Kingdom and New York, NY, USA, $1535 \mathrm{pp}$.

IPCC (2014a) Climate Change 2014: Impacts, Adaptation, and Vulnerability. Part A: Global and Sectoral Aspects. Contribution of Working Group II to the Fifth Assessment Report of the Intergovernmental Panel on Climate Change [Field, C.B., V.R. Barros, D.J. Dokken, K.J. Mach, M.D. Mastrandrea, T.E. Bilir, M. Chatterjee, K.L. Ebi, Y.O. Estrada, R.C. Genova, B. Girma, E.S. Kissel, A.N. Levy, S. MacCracken, P.R. Mastrandrea, and L.L. White (eds.)]. Cambridge University Press, Cambridge, United Kingdom and New York, NY, USA, 1132 pp.

IPCC (2014b)Climate Change 2014: Impacts, Adaptation, and Vulnerability. Part B: Regional Aspects. Contribution of Working Group II to the Fifth Assessment Report of the Intergovernmental Panel on Climate Change [Barros, V.R., C.B. Field, D.J. Dokken, M.D. Mastrandrea, K.J. Mach, T.E. Bilir, M. Chatterjee, K.L. Ebi, Y.O. Estrada, R.C. Genova, B. Girma, E.S. Kissel, A.N. Levy, S. MacCracken, P.R. Mastrandrea, and L.L. White (eds.)]. Cambridge University Press, Cambridge, United Kingdom and New York, NY, USA, pp. 688.

IPCC (2018) Summary for Policymakers. In: Global warming of $1.5^{\circ} \mathrm{C}$. An IPCC Special Report on the impacts of global warming of $1.5^{\circ} \mathrm{C}$ above pre-industrial levels and related global greenhouse gas emission pathways, in the context of strengthening the global response to the threat of climate change, sustainable development, and efforts to eradicate poverty. In press.

IPCC (2019a) Summary for policymakers. In: IPCC Special Report on the Ocean and Cryosphere in a Changing Climate. In press.

IPCC (2019b) Summary for policymakers. In: Climate Change and Land: an IPCC special report on climate change, desertification, land degradation, sustainable land management, food security, and greenhouse gas fluxes in terrestrial ecosystems. In press.

Jamero ML, Onuki M, Esteban M, Tan N (2018) Community-based adaptation in low-lying islands in the Philippines: challenges and lessons learned. Reg Environ Change 18:2249-2260. https://doi. org/10.1007/s10113-018-1332-8

Juhola S, Glaas E, Linnér B, Neset T (2016) Redefining maladaptation. Environ Sci Policy 55(1):135-140. https://doi.org/10.1016/j. envsci.2015.09.014

Kirkby P, Williams C, Huq S (2017) Community-based adaptation (CBA): adding conceptual clarity to the approach, and establishing its principles and challenges. Climate Dev 10(295):1-13. https://doi.org/10.1080/17565529.2017.137226

Klein RJT, Midgley GF, Preston BL, Alam M, Berkhout FGH, et al (2014) Adaptation opportunities, constraints, and limits. In: IPCC (2014) Climate change 2014 - impacts, adaptation, and vulnerability. Part A: global and sectoral aspects: Working Group II Contribution to the IPCC Fifth Assessment Report. Cambridge University Press, Cambridge 899-943. https://doi.org/10.1017/ CBO9781107415379

Klöck C, Nunn PD (2019) Adaptation to climate change in small island developing states: a systematic literature review of academic research. The Journal of Environment \& Development 28(2):196218. https://doi.org/10.1177/1070496519835895

Lewis SL, Brando PM, Phillips OL, Van der Heijden MF, Nepstad D (2011) The 2010 Amazon drought. Science 331(6017):554. https://doi.org/10.1126/science.1200807

Lopes DO, Procópio JG, Costa MS, Ribeiro MC (2021) Emergency aid as mitigation of the economic impacts caused by COVID19: a case study in a municipality in the Amazon region of Pará. Brazilian Journals of Business 3(2):2459-2473. https://doi.org/ 10.34140/bjbv3n3-031

Magrin GO, Marengo JA, Boulanger J-P, Buckeridge MS, Castellanos E, et al (2014) Central and South America. In: IPCC (2014) Climate change 2014: impacts, adaptation, and vulnerability. Part B: regional aspects: Working Group II Contribution to the IPCC Fifth Assessment Report. Cambridge University Press, Cambridge 1499-1566. https://doi.org/10.1017/CBO9781107415386

Marengo JA, Borma LS, Rodriguez DA, Pinho P, Soares WR et al (2013) Recent extremes of drought and flooding in Amazonia: vulnerabilities and human adaptation. Am J Clim Chang 2:87-96. https://doi.org/10.4236/ajcc.2013.22009

Marengo JA, Espinoza JC (2016) Extreme seasonal droughts and floods in Amazonia: causes, trends and impacts. Intern J Climatology 36(3):1033-1574. https://doi.org/10.1002/joc.4420

Marengo JA, Souza CM Jr, Thonicke K, Burton C, Halladay K et al (2018) Changes in climate and land use over the Amazon region: current and future variability and trends. Front Earth Sci 6:228. https://doi.org/10.3389/feart.2018.00228

Marengo JA, Tomasella J, Soares WR, Alves LM, Nobre CA (2012) Extreme climatic events in the Amazon basin: climatological and hydrological context of recent floods. Theoret Appl Climatol 107(1-2):73-85. https://doi.org/10.1007/s00704-011-0465-1

Maru YT, Smith MS, Sparrow A, Pinho PF, Dube OP (2014) A linked vulnerability and resilience framework for adaptation pathways in remote disadvantaged communities. Glob Environ Chang 28:337350. https://doi.org/10.1016/j.gloenvcha.2013.12.007

McNamara K, Bronen R, Fernando N, Klepp S (2018) The complex decision-making of climate-induced relocation: adaptation and loss and damage. Climate Policy 18(1):111-117. https://doi.org/ 10.1080/14693062.2016.1248886

McNamara KE, Clissold R, Westoby R, Piggott-McKellar A, Kumar R (2020) An assessment of community-based adaptation initiatives in the Pacific Islands. Nat Clim Chang 10:628-639. https://doi. org/10.1038/s41558-020-0813-1

Michetti M, Ghinoi S (2020) Climate-driven vulnerability and risk perception: implications for climate change adaptation in rural Mexico. J Environ Stud Sci 10:290-302. https://doi.org/10.1007/ s13412-020-00607-8

Moftakhari H, Shao W, Moradkhani H, AghaKouchak A, Sanders B et al (2021) Enabling incremental adaptation in disadvantaged communities: polycentric governance with a focus on non-financial capital. Climate Policy 21(3):396-405. https://doi.org/10. $1080 / 14693062.2020 .1833824$

Moran EF (1984) Human ecology in the Amazon. Interciencia 9:341-424

Nakashima DJ, Galloway McLean K, Thulstrup HD, Ramos Castillo A, Rubis JT (2012) Weathering uncertainty: traditional knowledge for climate change assessment and adaptation. UNESCO, Paris and Darwin. ISBN: 978-92-3-991968-3

Nascimento ACK (2017) Resiliência e adaptabilidade dos sistemas socioecológicos ribeirinhos frente a eventos climático extremos na Amazônia central. Masters' thesis, Universidade Federal do Amazonas.

Noble IR, Huq S, Anokhin YA, Carmin J, Goudou D, et al (2014) Adaptation needs and options. In: IPCC (2014) Climate change 2014: impacts, adaptation, and vulnerability. Part A: Global and Sectoral Aspects: Working Group II Contribution to the IPCC 
Fifth Assessment Report. Cambridge University Press, Cambridge 833-868. https://doi.org/10.1017/CBO9781107415379

Novalia W, Malekpour S (2020) Theorising the role of crisis for transformative adaptation. Environ Sci Policy 112:361-370. https:// doi.org/10.1016/j.envsci.2020.07.009

Nugent S (2009) Utopias and dystopias in the Amazonian social landscape. In: Adams C, Murrieta R, Neves W, Harris M (Eds) Amazon Peasant Societies in a Changing Environment. Political Ecology, Invisibility and Modernity in the Rainforest. Springer, London 21-32. https://doi.org/10.1007/978-1-4020-9283-1

Olsson L, Opondo M, Tschakert P, Agrawal A, Eriksen SH, et al (2014) Livelihoods and poverty. In IPCC (2014) Climate change 2014: impacts, adaptation, and vulnerability. Part A: Global and Sectoral Aspects: Working Group II Contribution to the IPCC Fifth Assessment Report. Cambridge University Press, Cambridge, pp 793-832. https://doi.org/10.1017/CBO9781107415379

Osuna VR, Börner J, Cunha M (2014) Scoping Adaptation Needs for Smallholders in the Brazilian Amazon: a municipal level case study. Change and Adaptation in Socio-Ecological Systems 1(1):12-25. https://doi.org/10.2478/cass-2014-0002

Oviedo AFP, Mitraud S, McGrath DG, Bursztyn M (2016) Implementing climate variability adaptation at the community level in the Amazon floodplain. Environ Sci \& Policy 63:151-160. https://doi. org/10.1016/j.envsci.2016.05.017

Padoch C, Pinedo-Vasquez M (1991) Flood-time on the Ucayali. Nat Hist 5:48-57

Piggott-McKellar AE, McNamara KE, Nunn PD, Watson JEM (2019) What are the barriers to successful community-based climate change adaptation? A review of grey literature. Local Environ 24(4):374-390. https://doi.org/10.1080/13549839.2019.1580688

Pinedo-Vasquez M, Pasqualle JB, Torres DC, Coffey K (2002) A tradition of change: the dynamic relationship between biodiversity and society in sector Muyuy, Peru. Environ Sci \& Policy 5:43-53. https://doi.org/10.1016/S1462-9011(02)00023-0

Pinho PF (2016) Watching Brazil but missing the story: an Amazonian inferno. Lasaforum 47(4):21-25

Pinho PF, Marengo JA, Smith MS (2015) Complex socio-ecological dynamics driven by extreme events in the Amazon. Reg Environ Change 15:643-655. https://doi.org/10.1007/s10113-014-0659-z

Platt RV, Ogra M, Kisak N, Manral U, Badola R (2021) Climate change perceptions, data, and adaptation in the Garhwal Himalayas of India. Climate Dev 13(2):95-106. https://doi.org/10.1080/17565 529.2020.1724069

Räsänen A, Juhola S, Nygren A, Käkönen M, Kallio M, Monge AM, Kanninen M (2020) Climate change, multiple stressors and human vulnerability: a systematic review. Reg Environ Change 16:22912302. https://doi.org/10.1007/s10113-016-0974-7

Robin E, Chazal C, Acuto M, Carrero R (2019) (Un)learning the city through crisis: lessons from Cape Town. Oxford Rev Educ 45:242-257. https://doi.org/10.1080/03054985.2018.1551197

Robinson LW, Berkes F (2011) Multi-level participation for building adaptive capacity: Formal agency-community interactions in northern Kenya. Glob Environ Chang 21(4):1185-1194. https:// doi.org/10.1016/j.gloenvcha.2011.07.012

Röpke C, Amadio S, Zuanon J, Ferreira EJG, de Deus CP et al (2017) Simultaneous abrupt shifts in hydrology and fish assemblage structure in a floodplain lake in the central Amazon. Sci Rep 7:40170. https://doi.org/10.1038/srep40170

Ruiz-Mallén I, Fernández-Llamazares A, Reyes-García V (2017) Unravelling local adaptive capacity to climate change in the Bolivian Amazon: the interlinkages between assets, conservation and markets. Clim Change 140(2):227-242. https://doi.org/10.1007/ s10584-016-1831-x

Satyamurty P, da Costa CPW, Manzi AO, Candido LA (2013) A quick look at the 2012 record flood in the Amazon Basin. Geophys Res Lett 40(7):1396-1401. https://doi.org/10.1002/grl.50245

Scoones I (1998) Sustainable rural livelihoods: a framework for analysis. Working Paper 72. Institute for Development Studies, Brighton.

Sherman M, Ford J, Llanos-Cuentas A, Valdivia M, Bussalleu J (2015) Vulnerability and adaptive capacity of community food systems in the Peruvian Amazon: a case study from Panaillo. Nat Hazards 77(3):2049-2079. https://doi.org/10.1007/s11069-015-1690-1

Sherman M, Ford J, Llanos-Cuentas A, Valdivia M (2016) Food system vulnerability amidst the extreme 2010-2011 flooding in the Peruvian Amazon: a case study from the Ucayali region. Food Security 8(3):551-570. https://doi.org/10.1007/s12571-016-0583-9

Smith RC (2011) Introduction: human society in the Várzea: a history of change and adaptation to contextual uncertainties. In: PinedoVasquez M, Ruffino ML, Padoch C, Brondízio ES (eds) The Amazon Varzea. The Decade Past and the Decade Ahead. Springer, London, pp 3-10. https://doi.org/10.1007/978-94-007-0146-5

Snyder PK (2010) The influence of tropical deforestation on the northern hemisphere climate by atmospheric teleconnections. Earth Interact 14:1-34. https://doi.org/10.1175/2010EI280.1

Stroeve J, Serreze M, Holland M, Kay J, Malanik J et al (2012) The Arctic's rapidly shrinking sea ice cover: a research synthesis. Clim Change 110(3-4):1005-1027. https://doi.org/10.1007/ s10584-011-0101-1

Takasaki Y, Barham BL, Coomes OT (2010) Smoothing income against crop flood losses in Amazonia: rain forest or rivers as a safety net? Review of Develop Econ 14(1):48-63. https://doi.org/ 10.1111/j.1467-9361.2009.00538.x

Tomasella J, Pinho PF, Borma LS, Marengo JA, Nobre CA et al (2013) The droughts of 1997 and 2005 in Amazonia: floodplain hydrology and its potential ecological and human impacts. Clim Change 116:723-746. https://doi.org/10.1007/s10584-012-0508-3

Vogt ND, Pinedo-Vasquez M, Brondízio ES, Almeida O, Rivero S (2015) Forest transitions in mosaic landscapes: smallholder's flexibility in land-resource use decisions and livelihood strategies from World War II to the present in the Amazon Estuary. Soc Nat Resour 28(10):1043-1058. https://doi.org/10.1080/08941 920.2015.1014603

Wilson GA (2012) Community resilience and environmental transitions. Earthscan, Oxford. https://doi.org/10.4324/9780203144916

Wilson RS, Herziger A, Hamilton M, Brooks JS (2020) From incremental to transformative adaptation in individual responses to climate-exacerbated hazards. Nat Clim Chang 10:200-208. https:// doi.org/10.1038/s41558-020-0691-6

Publisher's Note Springer Nature remains neutral with regard to jurisdictional claims in published maps and institutional affiliations. 